\title{
Bitlis İlindeki Kaba Yem Üretim Potansiyelinin Hayvan Varlığına Göre Yeterliliğinin Belirlenmesi
}

\author{
Emre BIÇAKÇ ${ }^{1}$, Semih AÇIKBAȘ ${ }^{2 *}$ \\ ${ }^{1}$ Süleyman Demirel Üniversitesi, Tarla Bitkileri Bölümü, Isparta \\ ${ }^{2}$ Siirt Üniversitesi, Tarla Bitkileri Bölümü, Siirt
}

\begin{abstract}
Öz
$\mathrm{Bu}$ çalışmanın amacı; Bitlis ilinin kaba yem potansiyeli ve hayvansal varlığının yem ihtiyacının belirlenmesi ve bu hususta karşılaşılan sorunların giderilmesine yönelik çözümlerin sunulmasıdır. Bu doğrultuda Bitlis ilinin agroekolojik özellikleri, kaba yem üretimi ve hayvan varlığı incelenmiştir. Bitlis ili tarım alanları dağılışına göre; toplam arazi varlığı 857.906 hektar(ha), çayır-mera alanı 297.662 ha ve yem bitkileri ekiliş alanı 59.096 ha olup, toplam arazi varlığının \% 41' ini oluşturmaktadır. Yem bitkileri ve çayır-mera alanlarından elde edilen toplam kaliteli kaba yem miktarı yaklaşık 315.081 tondur. Bitlis ili toplam hayvansal varlığı ise 61.748 baş büyükbaş ve 718.029 baş küçükbaş oluşturmaktadır. Hayvan sayılarının toplamı 272.297 Büyükbaş Hayvan Birimine (BBHB) denk gelmektedir. Yapılan bu çalışmada, Bitlis ilindeki mevcut hayvan sayısı, kaba yem üretim miktarının belirlenmesi ve kaba yem üretiminin mevcut hayvan potansiyeline yeterli olup olmadığı ortaya konulmaya çalışılmıştır. Yukarıda verilen sayısal veriler değerlendirildiğinde Bitlis ilinde kaliteli kaba yem açığının olduğu yapılan hesaplamalarla ortaya konulmuştur. Kaliteli kaba yem açı̆̆ının giderilmesi için; yem bitkileri ekim alanları artırılmalı, ekim nöbeti ile yem bitkileri tarımına öncelik verilmelidir. Ayrıca yem bitkilerinin verimlerini artırmaya yönelik ve çayır ve mera alanlarında ıslah çalışmaları yapılması gereklidir.
\end{abstract}

Anahtar kelimeler: Bitlis, Çayır-mera, Ekim Alanı, Hayvan Varlı̆̆ı, Yem Bitkileri.

\section{Determination of Roughage Production Potential for Farm Animals in Bitlis Province}

\begin{abstract}
The aim of this research is determine Bitlis province's producing power of roughage, the need for animal feed and offer solutions for the problems encountered. Accordingly, agroecological characteristics, roughage production and animal existence of Bitlis province are analyzed. According to the distribution of agricultural areas in Bitlis province; total land is 857.906 hectares, meadow-pasture area is 297.662 hectares and forage plants area is 59.096 hectares, which constitutes $41 \%$ of total land. The total amount of roughage obtained from feed crops and meadowpasture areas is approximately 315.081 tons. The total number of farm animals in Bitlis is 61.748 bovine and 718.029 ovine. The total number of animals corresponds to 272.297 Bovine unit. In this study, number of animals, roughage production, and the feed production sufficiency for the current number of animal were examined. When the data were evaluated, it was determined that there is a lack of quality forage production for the removal of quality roughage deficit; cultivation area of feed crops should be increased, feed crop gowing with crop rotation should be given priority. It is also necessary to carry out improvement activities in order to increase the yield of forage crops and in meadow and pasture areas.
\end{abstract}

Keywords: Bitlis, Grasslands, Cultivation Area, Animal potential, Forage Crops.

\footnotetext{
*Sorumlu yazar: semihacikbas@siirt.edu.tr

Geliş Tarihi: 10/12/2017 Kabul Tarihi: 19/02/2018
} 


\section{Giriş}

Ülke hayvancılığımızın geliştirilmesinde çözülmesi gereken en önemli sorunlardan biri kaliteli, ucuz ve bol kaba yem ihtiyacının düzenli karşılanmasıdır [1]. Yem bitkileri, çayır ve mera (YBÇM) tarımı hayvanların ihtiyacı olan yemi en ucuz ve bol miktarda sağlayan kaynaktır. Hayvan beslemede çeşitli endüstri artıkları, küspeler, posalar ve bazı tahıl taneleri kullanılsa da, bunların miktarı YBÇM tarımından sağlanan yeme göre oldukça düşük seviyelerdedir. Yem bitkileri, çayır ve mera tarımında yüksek verim alındığı gibi, üretim de ucuza mal olmaktadır. Bu nedenle, hayvancılığı ileri gitmiş ülkelerde hayvancılık esas olarak YBÇM tarımına dayalı olarak yürütülmektedir. Özellikle ABD, Kanada, Arjantin ve Avustralya gibi geniş doğal veya kültür meralarına sahip ülkelerde çok ucuza hayvansal üretim yapılmakta olup, ihraç edilebilecek miktarda yem üretilmektedir [2]. Türkiye'de çayır mera alanları tarım alanlarının büyük bir kısmını içermektedir ve çayır mera alanları 14.6 milyon hektar ile toplam ülke alanının \%18.7'lik bir kısmını oluşturmaktadır [3].

Kuru ot, yeşil yemler ve silo yemleri gibi kaba yemlerin maliyetlerinin düşük olması hayvancılık işletmelerinin karlılığını artıran önemli bir faktördür [4]. Hayvansal üretim maliyetlerinin \% 70'ini yem girdilerinin oluşturması, ucuz yem kaynakları kullanımının karlılığa etkisini açıklamaya yeterlidir [5]. Bu nedenle, hayvancılık işletmelerinin kaliteli kaba yem gereksinimini karşılamak için çayır-meraların 1slahı, yem bitkisi üretim alanlarının artırılması, ucuz ve alternatif diğer kaba yem kaynaklarının hayvansal üretime kazandırılması ve kaliteli kaba yem üretim tekniklerinin üreticilere aktarılması gerekmektedir [5;6].

Hayvan beslemede kaliteli kaba yemler, ucuz bir kaynak olmasının yanı sıra, geviş getiren hayvanların rumen mikro flora ve faunasının gelişimi için gerekli protein, yağ ve selülozu içermesi, mineral ve vitaminlerce zengin olması, hayvanların performansını iyileştirmesi, beslemeye bağlı pek çok metabolik hastalığın önlenmesi ve yüksek kalitede hayvansal ürün sağlaması bakımından da önemlidir [7]. Yem bitkileri tarımı, çayır ve meraların üzerindeki aşırı otlatma baskısını hafifletecek, tahıl-nadas sistemlerinde münavebeye girerek nadas alanlarının daralmasına neden olacak ve sonuçta ülkemizdeki erozyon miktarını da azaltacaktır [6]. Tüm dünyada YBÇM tarımının bu değerli özelliklerinin bilinmesine karşılık, Yurdumuzda hayvan beslenmesi, geniş ölçüde verim güçlerini yitirmiş olan doğal çayır ve meralara, anızlara ve tahıl samanına dayanmaktadır [2]. Türkiye'de son yıllarda Gıda Tarım ve Hayvancılık Bakanlığının desteklemeleri ile yem bitkileri ekimi, üretimi ve suca zengin kaba yemlerden silaj yapımı önemli düzeyde artmıştır [8]. Buna ek olarak hayvancılığın çok olduğu Doğu Anadolu Bölgesi'nde yapılan desteklemelerin yembitkileri alanında artarak ve çeşitlendirilerek devam ettirilmesi gereklidir [9].

Doğu Anadolu Bölgesi karasal iklim kuşağında olup, \% 53.4'ü çayır ve meralardan oluşmaktadır. Ancak bu alanlardan ve ekilen yem bitkilerinden elde edilen kaba yem hayvan varlı̆̆ının ihtiyacını karşılayamamaktadır. Türkiye'de ekilen yonca ve korunganın \% 44.5 'i, hayvan varlığının yaklaşık \% 30'u Doğu Anadolu Bölgesinde bulunmaktadır [2].

Bitlis iline yakın coğrafi konumda bulunan Van ve Siirt illerinde kaba yem potansiyelinin belirlenmesine yönelik yapılan çalışmalarda da kaliteli kaba yem açığı olduğu görülmektedir. Van ilinin kaba yem açığı $\% 36$ düzeyindedir. Siirt ilinde ise hayvan varlığının sadece $\% 41$ 'ine yetecek kaba yem mevcut olduğu görülmüştür [10;11].

Bitlis, önemli çayır-mera alanlarına sahip olmasına karşın, hayvansal üretim noktasında yeterli olduğu söylenemez. Ülkemizin birçok bölgesinde olduğu gibi Bitlis'te de çayır ve meraların bilinçsiz kullanımı, bu arazilerin verim potansiyelini düşürmekte ve oldukça yıpratmakta olup ucuz yem kaynaklarının verimsiz kullanılmasına neden olmaktadır. Ülkemiz yem bitkisi tarımında karşılaşılan başlıca problemler; mono kültür tarım, çiftçi eğitim ve yayım hizmetlerinin yetersizliği, üreticilerle arzu edilen seviyede iletişim kurulamayışı ve çiftçilerin büyük bir bölümü tarafından geleneksel tarım tekniklerinin kullanımına devam edilmesidir [12]. Hayvanlarda görülen verim düşüklüğünün nedenlerinden biri olan ve bunun sonucunda insanlarımızın yeterli düzeyde hayvansal proteinle beslenememesi ile sonuçlanan kaliteli kaba yem yetersizliği, ülke tarımımızda hayvancılığımıza kaliteli yem sağlayan sektörlerinin sorunlarından kaynaklanmaktadır [13;14].

Bitlis ilinin coğrafi konumu gereği büyük bir bölümünün dağlik oluşu, iklim şartlarının karasal iklimi olmas1, meralarının verimlerinin istenilen düzeyde olmayışı ve bulunduğu bölge itibariyle pazarlama, ticaret, bakım, yetiştirme, besleme vb. gibi birçok faktör hayvansal üretimi olumsuz yönde etkilemektedir. Yeterli oranda kaliteli kaba yem ile hayvanların beslenememesi de en önemli sorunların 
başında gelmektedir. Bölgede yerli ırkların fazlalığı ve kültür ırklarının azlığı, eğitim seviyesinin düşük olması, bilinçsiz şekilde meraların kullanılması da hayvansal ürün elde etmede zorlukları artırmaktadır. Bu bilgilerin 1şı̆̆ında Bitlis ilindeki mevcut hayvan sayısı, kaba yem potansiyeli, çayır mera ve yem bitkilerinin mevcut durumu, kaliteli kaba yem durumunun yeterliliğinin belirlenmesi, sorunları ve çözüm önerileri hakkında durum analizi yapılmıştır.

\section{Bitlis İlinin Agro-Ekolojik Özellikleri ve Arazi Varlığı}

Bitlis, Doğu Anadolu Bölgesi'nin Yukarı Fırat ve Yukarı Murat bölümlerinin sınırı üzerinde bir ildir. Doğuda Van Gölü ve Van ili, güneyde Siirt, batıda Muş, kuzeyde de Ağrı illeriyle çevrilmiştir. Yüzölçümü 6707 kilometrekaredir.

Bitlis ili Doğu Anadolu'nun en dağlık kısımlarından birini teşkil eder. Bitlis ilinde karasal iklim hâkimdir. Kışlar soğuk ve uzun, yazlar kısa ve sıcaktır. Önemli akarsuyu yoktur. Yalnız çevredeki dağlardan çıkıp Van Gölü'ne dökülen birçok ufak dereler vardır. Ormanlık alanlar oldukça fazla yer tutar. Bitlis, bu bakımdan Doğu Anadolu'nun birçok illerinden ileri bir durumdadır. Bütün yüzölçümünün $\% 11$ 'i ormanlıktır. Tarıma elverişli topraklar bütün il yüzölçümünün \% 7'si kadardır. En çok buğday ekilir. Geleneğe bağlı olarak darı ekimi de gelişmiştir. Bitlis ilinde en fazla karaman tipi koyun ve farklı ırklardan sığır yetiştirilir. Arıcılık da oldukça ileri seviyededir.

Bitlis ilinde 2016 yılı verilerine göre [15], toplam arazi varlığ 857.906 ha olup, 297.662 ha alanı çayırmera, 261.264 ha alanı Göl, 164.756 ha alanı ormanlık ve 134.224 ha alan da tarım arazisini oluşturmaktadır. Toplam arazi varlığı içinde en fazla alanı \% 34.7 ile çayır-mera alanları kaplamaktadır. Mevcut arazi varlığının \% 15.6'lık kısmında tarım yapılabilmektedir. Bitlis ilinin toplam arazi varlığ ve dağılımı Tablo 1 'de verilmiştir.

Tablo 1. Bitlis İlinin Toplam Arazi Varlığının ve Dağılımı [16]

\begin{tabular}{cc}
\hline \multicolumn{2}{c}{ Toplam Arazi Varlığının Dağılımı } \\
\hline Tarım alanı & 134.224 ha \\
Çayır-Mera alanı & 297.662 ha \\
Orman alanı & 164.756 ha \\
Göl alanı & 261.264 ha \\
\hline Toplam & 857.906 ha \\
\hline
\end{tabular}

Toplam tarım arazilerinin dağılımına göre, en fazla alanı \% 82.7'lik oranıyla tarla alanları oluşturmaktadır. Sırasıyla \% 10.9'u nadas alanı (14.646 ha), \% 4.1'i meyve alanı (5.490 ha), \% 2.2'sini de sebze alanı (3.010 ha) oluşturmaktadır. Bitlis ilinin ekilebilir tarım alanlarının dağıımı Tablo 2'de verilmiştir.

Tablo 2. Bitlis İli Tarım Alanlarının Dağılımı [16]

\begin{tabular}{cc}
\hline \multicolumn{2}{c}{ Tarım Alanlarının Dağılımı } \\
\hline Tarla alanı & 111.078 ha \\
Meyve alanı & 5.490 ha \\
Sebze alanı & 3.010 ha \\
Nadas alanı & 14.646 ha \\
\hline Toplam & 134.224 \\
\hline
\end{tabular}




\section{Bitlis İlindeki Büyükbaş ve Küçükbaş Hayvan Varlığı}

Bitlis ilindeki büyükbaş hayvan sayısı Tablo 3'de verilmiştir. Tablo 3 incelendiğinde; 53.410 baş kültür, melez ve yerli sığır olduğunu ve 8.338 baş da Manda bulunmaktadır. İldeki büyükbaş hayvanların \% 60.4 'ü düşük verimli olan irklardan oluşmaktadır.

Tablo 3. Bitlis İlindeki Büyükbaş Hayvan Sayıs1 [16]

\begin{tabular}{lc}
\hline \multicolumn{2}{l}{ Bitlis İlindeki Büyükbaş Hayvan Sayısı (Baş) } \\
\hline Sığır (kültür) & 16.107 \\
Manda & 8.338 \\
Sığır (melez) & 25.832 \\
Sığır (yerli) & 11.466 \\
\hline Toplam & 61.748 \\
\hline
\end{tabular}

Bitlis ili küçükbaş hayvan sayısı Tablo 4'de verilmiştir. Tablo 4 incelendiğinde, Bitlis de 430.331 baş koyun ve 287.698 baş de keçi olduğu görülmektedir. Bitlis de toplam 61.748 adet büyükbaş ve 718.029 adet küçükbaş vardır. Hayvan sayılarını tek bir sayıya dönüştürüp hesaplayabilmek ve otlatma kapasitelerinin belirlenebilmesi için Büyükbaş Hayvan Birimi (BBHB) kullanılmaktadır. Büyükbaş Hayvan Birimi; hayvan sayısının, bir büyükbaş hayvan birimi olan $500 \mathrm{~kg}$ canlı ağırlığına çevrilme şeklini ifade eder. Meraları değerlendiren değişik ırk ve cinslere ait hayvanların sayısını belirlemede yaşanan sıkıntıları ortadan kaldırmak için uluslararası kullanılan BBHB'ne çevirme katsayıların kullanılması hesaplamalarda kolaylıklar sağlamaktadır [17]. Bitlis ilindeki toplam 61.748 baş büyükbaş ve 718.029 baş küçükbaş BBHB'ne çevrildiğinde 272.297 Büyükbaş Hayvan Birimine denk gelmektedir.

Tablo 4. Bitlis İlindeki Küçükbaş Hayvan Sayısı [16]

\begin{tabular}{lc}
\hline $\begin{array}{l}\text { Bitlis İlindeki Küçükbaş Hayvan } \\
\text { Sayısı }\end{array}$ & Baş \\
\hline Koyun & 430.331 \\
Keçi & 287.698 \\
\hline Toplam & 718.029 \\
\hline
\end{tabular}

\section{Bitlis İlindeki Kaba Yem Üretim Potansiyeli}

Bitlis ilindeki kaliteli kaba yem kaynakları çayır-mera alanlarından ve tarla tarımı içerisinde yer alan yonca, korunga, silajlık mısır ve diğer yem bitkilerinden elde edilmektedir. Yem bitkilerinden ve çayırmera alanlarının dağılımı, elde edilen kaba yem miktarı ve dekara verimini gösteren sayılar Tablo 5'de verilmiştir. Tablo 5 incelendiğinde çayır-mera alanlarının 2.976.620 dekar(da) olduğu ve bu alanlardan yaklaşık 208.363 ton kaliteli kaba yem elde edildiği düşünülmektedir. Kaliteli yem kaynağı olarak en fazla elde yem bitkisi olan yoncadan 461.315 da alandan yaklaşık 76.117 ton ürün elde edilmektedir. Korungadan 125.880 da alandan yaklaşık 13.595 ton ve mısır silajından 3.760 da alandan yaklaşık 17.006 ton kaliteli kaba yem elde edilmektedir. Kaliteli kaba yem kaynaklarından 3.567.575 da alandan toplam 315.081 ton ürün elde edilmektedir. 
Tablo 5. Kaba Yem Kaynakları, Arazi Varlığı ve Üretim Miktarı [16]

\begin{tabular}{llll}
\hline \multicolumn{4}{c}{ Kaba Yem Kaynakları, Arazi Varlığı ve Üretim Miktarı } \\
\hline Ürün Ad1 & $\begin{array}{l}\text { Kaba Yem Kaynağı } \\
\text { Alanı (da) }\end{array}$ & Üretim (ton) & Verim (kg/da) \\
\hline Çayır ve Meralar (Kuru ot) & 2.976 .620 & 208.363 & 70 \\
Misır silaj1 & 3.760 & 17.006 & 4.523 \\
Yonca (Kuru ot) & 461.315 & 76.117 & 165 \\
Korunga (Kuru ot) & 125.880 & 13.595 & 108 \\
\hline Toplam & 3.567 .575 & 315.081 & \\
\hline
\end{tabular}

\section{Sonuç}

Bitlis ilinde BBHB cinsinden değeri 272.297 adet olup, BBHB için günlük $12.5 \mathrm{~kg}$ kuru ot ihtiyac1 hesabıyla 12.5 x $272.297=3.403$ ton günlük kaliteli kaba yem ihtiyacı vardır. Buna bağlı olarak yıllık kaliteli kaba yem hesabı olarak 3.403 ton x $365=1.242 .355$ tondur. Bu ihtiyacın yalnızca 109.718 tonu ekilen yem bitkilerinden karşılanmaktadır. Çayır-Mera alanlarından yaklaşık olarak ortalama $70 \mathrm{~kg} / \mathrm{da}$ kuru ot elde edildiği düşünülmektedir. Bu hesaba göre çayır meralardan 2.976 .620 da x $70 \mathrm{~kg}=208.363$ ton kaba yem elde edilmekte olup; bu değer yem bitkileri tarımı ile üretilen 109.718 ton ile toplandığında Bitlis ilinde elde edilen yıllık toplam kaliteli kaba yem miktarı 315.081 ton olduğu görülmektedir. Büyükbaş hayvan birimine göre yıllık toplam kaliteli kaba yem ihtiyacından (1.242.355 ton) üretilen toplam kaba yem miktarı çıkarıldığında kaliteli kaba yem açığının 927.274 ton olduğu görülmektedir. Yem açığının bir kısmı saman, tarla atıkları, otlatılan nadas alanları, kabuk, kavuzlar, kes vb. gibi kalitesiz kaba yemler ile kesif yem, arpa ve buğdaydan oluşan karışımlarla yem açığı giderilmeye çalışılmaktadır.

Kaliteli kaba yem açığının giderilmesi için nadas alanlarına ve meyve bahçelerinin altına tek yıllık yem bitkilerinin ekilmesi, çayır-mera alanlarının ıslah edilmesi, çayır-mera alanlarında amenajman ilkelerine uyulması, yem bitkileri ekiminin artırılması için üreticilerin teşvik edilmesi ve eğitilmesi adına etkinliklerin yapılması, yem bitkilerinde sertifikalı tohumluk kullanılmasına dikkat edilmeli, yem bitkileri ekimine ve alet-ekipman için devlet desteklerinin artırılması ve tarla tarımı içerisindeki yem bitkileri ekim nöbeti ile ekim oranın artırılması gibi önlemler alınması büyük önem arz etmektedir. 


\section{Kaynaklar}

1. Alçiçek A., Kiliç A., Ayhan V., Özdoğan M. 2010. Türkiye'de Kaba Yem Üretimi ve Sorunlari, Türkiye Ziraat Mühendisliği VII. Teknik Kongresi, Cilt:2, pp1071-1080, 11-15 Ocak 2010, Ankara.

2. Açıkgöz E., Hatipoğlu R., Altınok S., Sancak C., Tan A., Uraz D. 2005. Yem Bitkileri Üretimi ve Sorunlar, 1. Türkiye Ziraat Mühendisliği VI. Teknik Kongresi, pp503-518, 3-7 Ocak 2005, Ankara.

3. TÜİK, 2015. Bitkisel Üretim İstatistikleri, https://biruni.tuik.gov.tr/bitkiselapp/bitkisel.zul

4. Bilgen H., Alçiçek A., Sungur N., Eichhorn H., Walz O. P. 1996. Ege Bölgesi Koşullarında Bazı Silajlık Kaba Yem Bitkilerinin Hasat Teknikleri ve Yem Değeri Üzerine Araştırmalar. Hayvanc1lık'96 Ulusal Kongresi, Cilt 1, 781-789.

5. Serin Y., Tan M., 2001. Yem Bitkileri Kültürüne Giriş. Atatürk Üniversitesi Ziraat Fakültesi Yayınları, No: 206, 217s., Erzurum.

6. Yolcu H., Tan M. 2008. Ülkemiz Yem Bitkileri Tarımına Genel Bir Bakış. Tarım Bilimleri Dergisi, 14(3): 303-312.

7. Alçiçek A., Karaayvaz K. 2003. Sığır Besisinde Mısır Silajı Kullanımı. Animalia 20 (3): 18-76.

8. Eker, M. M. 2006. Türk Tarımının Dünü Bugünü ve Geleceği Hakkında Genel Değerlendirme, Tarım ve Köyişleri Bakanı 2007 Yı1ı Mali Bütçe Konuşması Metni.

9. Şahin K., Yılmaz İ. H., 2009. The Effects of Subsidizing Forage Production on Animal Production in Van, Turkey. Journal of Animal and Veterinary Advances, 8(3): 492-495.

10. Turan N., Altuner F. 2014. Van İlinde Kaba Yem Üretim Potansiyeli, Sorunlar ve Çözüm Önerileri. Türkiye Tarımsal Araştırmalar Dergisi 1 (1): 91-97.

11. Turan N., Özyazıcı M. A., Yalçın Tantekin G. 2015. Siirt İlinde Çayır Mera Alanlarından ve Yem Bitkilerinden Elde Edilen Kaba Yem Üretim Potansiyeli. Türkiye Tarımsal Araştırmalar Dergisi 2 (1) : 69-75.

12. Balabanlı C., Bıçakçı E. 2016. Yozgat Yöresinde Kaba Yem Üretim Potansiyeli Ve Hayvansal Üretim Açısından Önemi, 1. Uluslararası Bozok Sempozyumu, pp97-102. 5-7 Mayıs 2016, Yozgat.

13. Avcıoglu R., Soya H., Açıkgöz E., Tan A. 2000. Yem bitkileri Üretimi, Türkiye Ziraat Mühendisligi V. Teknik Kongresi, 1. Cilt, pp567 585. 17-21 Ocak 2000, Ankara.

14. Alçiçek A. 2001. Süt İneklerinin Yemlenmesinde Yeni Teknikler. Ege Tarımsal Arastırma Enstitüsü Müdürlügü Yayınları, No: 100.

15. Web-1: http://www.nkfu.com/bitlis-ili-cografi-ozellikleri-hakkinda-bilgi/, consulted 10 october 2017

16. Bitlis İl Gıda Tarım ve Hayvancılık Müdürlüğü, 2017

17. Gökkuş A., Koç A., Çomaklı B. 1995. Çayır-Mera Uygulama Kılavuzu. Atatürk Üniversitesi Ziraat Fakültesi Yayınları No: 142: 49-50. 